\title{
Laser refractive surgery in diabetic patients: a review of the literature
}

This article was published in the following Dove Press journal:

Clinical Ophthalmology

31 October 2012

Number of times this article has been viewed

\author{
Leopoldo Spadea' \\ Maria Pia Paroli \\ 'University of L'Aquila, Department \\ of Biotechnological and Applied \\ Clinical Sciences, Eye Clinic, L’Aquila, \\ 2University of Rome "La Sapienza", \\ Department of Surgical Sciences, \\ Eye Clinic, Rome, Italy
}

Background: The purpose of this study was to evaluate the current recommendations regarding laser refractive surgery in patients with diabetes mellitus and to assess whether these patients make appropriate candidates for laser vision correction.

Methods: A literature search was conducted to identify current research on the ocular complications of diabetes and original publications on laser refractive surgery in diabetic patients.

Results: Diabetes was associated with several ocular complications. Initially the US Food and Drug Administration listed these complications as justification to advise against refractive surgery in patients with diabetes. However, recent studies on laser in situ keratomileusis in diabetic patients indicate that this procedure may be safe in diabetic patients with very well controlled systemic disease and no ocular manifestations.

Conclusion: Laser refractive surgery may be performed safely in a very selected group of patients with diabetes.

Keywords: diabetes, laser in situ keratomileusis, photorefractive keratectomy, refractive surgery

\section{Introduction}

Refractive surgery is a term used to describe a variety of eye surgeries performed to correct refractive errors and thereby reduce or eliminate a person's need for eyeglasses or contact lenses. Refractive errors include myopia (nearsightedness), hyperopia (farsightedness), and astigmatism. The most popular refractive surgery today is laser in situ keratomileusis (LASIK), a laser vision correction procedure that improves eyesight by reshaping the front surface of the eye with an excimer laser. In LASIK, an extremely sharp keratome is used to create a hinged flap of corneal epithelium and stroma. The flap is folded back, and a laser is programmed to cut precise amounts of tissue from the corneal stromal bed. Once the right amount of correction has been achieved, the flap is put back in its original place without sutures. Other common laser procedures for vision correction include epithelial laser in situ keratomileusis (Epi-LASIK), laser epithelial keratomileusis, and photorefractive keratectomy (PRK). In these techniques, the laser is used to refigure the curvature of the surface of the cornea. There are also nonlaser refractive surgical procedures. Although these are not as popular as LASIK and other laser procedures, they may be the surgery of choice in some cases. These procedures include implantable lenses, implanted corneal segments, astigmatic keratectomy, and refractive lens exchange. More than $90 \%$ of refractive eye surgeries performed in the US are LASIK procedures. Researchers are currently investigating a number of emerging refractive surgery technologies.
Correspondence: Leopoldo Spadea

Via Benozzo Gozzoli 34, 00I42

Rome, Italy

Tel +3908 6231 967।

Fax +390862319641

Email Ispadea@cc.univaq.it 
The US Food and Drug Administration (FDA) initially approved PRK for laser vision correction in the early 1990s. At that time, the FDA established a list of ocular and systemic contraindications to refractive surgery. Included among the relative systemic contraindications was diabetes mellitus. When this recommendation was issued, limited data were available on the outcome of refractive surgery in diabetic patients because refractive surgery was a relatively new field at that time, so the FDA based its recommendation primarily on documented outcomes of nonlaser ocular surgery in patients with diabetes. ${ }^{1,2}$ As justification, they expressed a number of concerns, including the possibilities that surgical procedures might worsen ocular disease and ultimately result in compromised refractive outcomes, and that the abnormal recovery response in these patients could result in significant corneal complications. When the FDA approved LASIK several years later, the same recommendations were applied. ${ }^{3}$ A recent guideline from the American Academy of Ophthalmology cataloged well controlled diabetic disease as a relative contraindication and only uncontrolled disease as an absolute systemic contraindication. ${ }^{4}$ Nevertheless, these concepts have remained confusing despite this guideline, and in practice, patients with systemic disorders are routinely excluded by most surgeons, even in asymptomatic and stabilized patients, as reflected in the methods sections of most publications. Moreover, contraindication of these systemic diseases for refractive surgery has not been supported by the literature, and the few published reports are based on isolated cases and small series with contradictory opinions from different expert physicians. The reason for these exclusions was the risk of a potentially damaging effect on the postoperative healing properties of the cornea, and that surgery theoretically could trigger a latent predisposition for significant scarring. These concepts were first introduced with PRK because of the mechanism of healing involved with this technique, in which the corneal stroma is exposed for a significant postoperative period until re-epithelialization is complete. ${ }^{2}$ However, subsequent evolution of LASIK as the main photorefractive procedure did not change these guidelines significantly, despite the marked improvement in the healing process that occurs with the LASIK technique.

Recently, several studies have attempted to clarify precisely which diabetes, if any, predisposes the patient to a higher risk of complications and adverse events, and whether some patients may be acceptable candidates for corneal refractive surgery. On the other side, the use of contact lens by diabetic individuals is not without risk. In fact, one study has reported that use of soft contact lenses modifies central corneal thickness and the morphologic characteristics of the corneal endothelium more frequently in diabetic patients than in normal subjects. ${ }^{5}$

The purpose of this review is to re-evaluate the current recommendations excluding patients with diabetes from laser refractive surgery by reviewing the corneal complications of diabetes and examining the current literature on the outcomes of refractive surgery and other ocular surgeries in this patient population.

\section{Ocular involvement in diabetes}

Diabetes mellitus affects more than 285 million people worldwide and has prevalence in the US of $4 \%-8 \%$ in the general population. Unfortunately, the incidence of diabetes continues to grow, as indicated by high rates of impaired fasting glucose levels, increasing rates of obesity, and a trend toward more sedentary lifestyles. In fact, the number of people with diabetes is expected to increase to 439 million by 2030 , according to the International Diabetes Federation. ${ }^{6,7}$ Retinopathy, neuropathy, and nephropathy are the most widely recognized complications of the disease. Diabetic retinopathy, as a leading cause of blindness, has attracted the major thrust of both clinical and basic research. It is a frequent complication of both type 1 and type 2 diabetes, and is considered the fifth most common cause of legal blindness in the US. ${ }^{8}$ Signs of diabetic retinopathy occur in $95 \%$ of type 1 diabetics and $60 \%$ of type 2 diabetics with a disease duration longer than 20 years. More severe cases of proliferative diabetic retinopathy are seen in patients suffering from type 1 diabetes. Tight control of hyperglycemia, blood lipids, and blood pressure has been shown to be beneficial in preventing development and progression of diabetic retinopathy. ${ }^{9-11}$ Clinical ophthalmological management of this condition now routinely includes photocoagulation and vitreoretinal surgery. Various systemic and local medications are also being extensively examined, both in basic research and in clinical trials, to determine their clinical efficacy in managing the complications of diabetic retinopathy. ${ }^{12}$

In addition to causing retinopathy, diabetes mellitus affects the eyes in many other ways, with diabetic papillopathy, neovascular glaucoma, cataract, ptosis, oculomotor nerve palsies, inflammation of eyelids, and orbital infections all being well recognized ocular complications of diabetes mellitus. ${ }^{13}$ Cataract is considered a major cause of visual impairment in diabetic patients because the incidence and progression of cataract is elevated in patients with diabetes mellitus. ${ }^{14,15}$ The association between diabetes and cataract formation has been shown in clinical epidemiological and basic research studies. 
Due to increasing numbers of type 1 and type 2 diabetics globally, the incidence of diabetic cataracts is steadily rising. Even though cataract surgery, the most common surgical ophthalmic procedure worldwide, is an effective cure, elucidation of mechanisms to delay or prevent the development of cataract in diabetic patients remains a challenge. Furthermore, patients with diabetes mellitus have higher complication rates following cataract surgery. ${ }^{16}$ Both diabetes and cataract pose an enormous health and economic burden, particularly in developing countries, where treatment of diabetes is insufficient and cataract surgery is often inaccessible. ${ }^{17}$

A significant proportion of diabetic patients develop corneal lesions during their lifetime. These complications include superficial punctate keratopathy, punctate epithelial erosions, persistent epithelial defects, recurrent corneal erosions, filamentary keratitis, decreased corneal sensitivity, neurotrophic keratopathy, tear dysfunction, endothelial dysfunction, and corneal ulcers. ${ }^{18-26}$ Keratopathy in the presence of diabetes should be considered as a potential sight-threatening condition, and so must be given appropriate clinical attention and increased research interest. For this reason, it is important to investigate the mechanism of diabetic keratopathy, and from this, hopefully establish improved techniques to prevent and treat the condition.

\section{Corneal changes}

A vast number of changes occur in the corneal epithelium of patients with diabetes. Abnormalities in the shape of epithelial cells, ${ }^{27-29}$ epithelial basement membrane thickening and multilayering, ${ }^{30,31}$ and a number of abnormalities in the basement membrane anchoring complex have been described. ${ }^{32,33}$ These abnormalities are likely responsible for the delayed epithelial healing observed in diabetic eyes postoperatively. ${ }^{34}$ These changes may also explain the compromised epithelial barrier function observed in the eyes of many diabetic patients. ${ }^{35-37}$

Corneal epithelial complications are thought to be common $(60 \%-80 \%)$ among diabetic patients, especially in those with other ocular and systemic complications of the disease. ${ }^{23,38}$ Corneal neuropathy occurs within the setting of systemic diabetic neuropathy, and manifests clinically as decreased corneal sensation..$^{20,39-42}$ Sequelae of reduced corneal sensation include impaired cellular adhesion, decreased mitosis, and impaired healing. ${ }^{43,44}$

Morphological abnormalities of the corneal endothelium are often seen in diabetic patients. These abnormalities include a decreased percentage of hexagonal cells, a higher rate of cell loss, and decreased cell density. ${ }^{21,45}$ As a result, intracellular interdigitation occurs, allowing excess fluid to leak into the corneal stroma. ${ }^{46,47}$ Because corneal transparency and thickness depend on a healthy, hydrophilic stroma, disturbances within the stroma can cause significant problems.

\section{Ocular surgery in diabetes}

The link between diabetes and increased surgical infection risk is widely accepted. The pathophysiology behind this phenomenon is multifactorial. Research has clearly demonstrated neutrophil chemotaxis, phagocytosis, and intracellular bactericidal activity as being impaired in diabetic patients with hyperglycemia. ${ }^{48,49}$ The impaired immune response in diabetic patients is often exacerbated by vascular insufficiency, which is common in these patients. ${ }^{50}$ As a result of the impaired immune response, diabetic patients are at increased risk of post-surgical infections. The link between diabetes and surgical site infections is very well established and documented in the literature. ${ }^{51}$ There are no large-scale studies to determine if the link between surgical site infections and diabetes extends to surgical incisions involving the eye; however, there are many anecdotal case reports of postoperative infections in these patients.

\section{LASIK and PRK in diabetic patients}

For years, the only data supporting or refuting the FDA and American Academy of Ophthalmology recommendations regarding PRK and LASIK in patients with diabetes were a small assortment of case reports. Recently, several retrospective studies have examined visual outcomes in these patients after LASIK surgery, and have started to reveal a better understanding of outcomes and risks of laser vision correction in this patient population. Since the beginning of laser refractive surgery, the FDA, guided by the recommendations of the first excimer laser companies, established a group of absolute and relative contraindications for the procedure, which included ocular and systemic diseases. The systemic diseases include autoimmune and connective tissue disorders, such as rheumatoid arthritis, systemic lupus erythematosus, ankylosing spondylitis, psoriatic arthritis, Sjögren's syndrome, and other types of systemic vasculitis. Diabetes mellitus, antecedent keloid formation, immunosuppression, treatment with certain drugs, and, recently, atopia and allergic conjunctivitis, were also included as relative contraindications or risk disorders.

In PRK, the laser is used to refigure the curvature of the surface of the cornea. This requires removal of the corneal epithelium, and this is the part of PRK that concerns us with regard to diabetic patients. The epithelium may not heal as 
well in diabetic patients. Although not all studies support this concern, patients with diabetes mellitus are probably not good candidates for PRK because of poorer postoperative healing that could resolve in a dense stromal haze (Figure 1). Laser epithelial keratomileusis and Epi-LASIK are essentially a variation of the PRK technique. However, Cobo-Soriano et al did not find any difference regarding time of re-epithelialization, number of postoperative visits, significant haze, or functional outcome relative to that observed in healthy patients undergoing laser epithelial keratomileusis procedures. ${ }^{2}$ People with diabetes can have excimer laser surgery, but should proceed with care because they might face the following problems.

\section{Visual alterations due to changes in blood glucose control}

It has been long recognized that major changes in glucose levels can cause short-term changes in vision. As a result, people with diabetes may experience blurry vision with their newly fitted contact lenses or spectacles if their blood glucose is not under control. Transient hyperopic changes
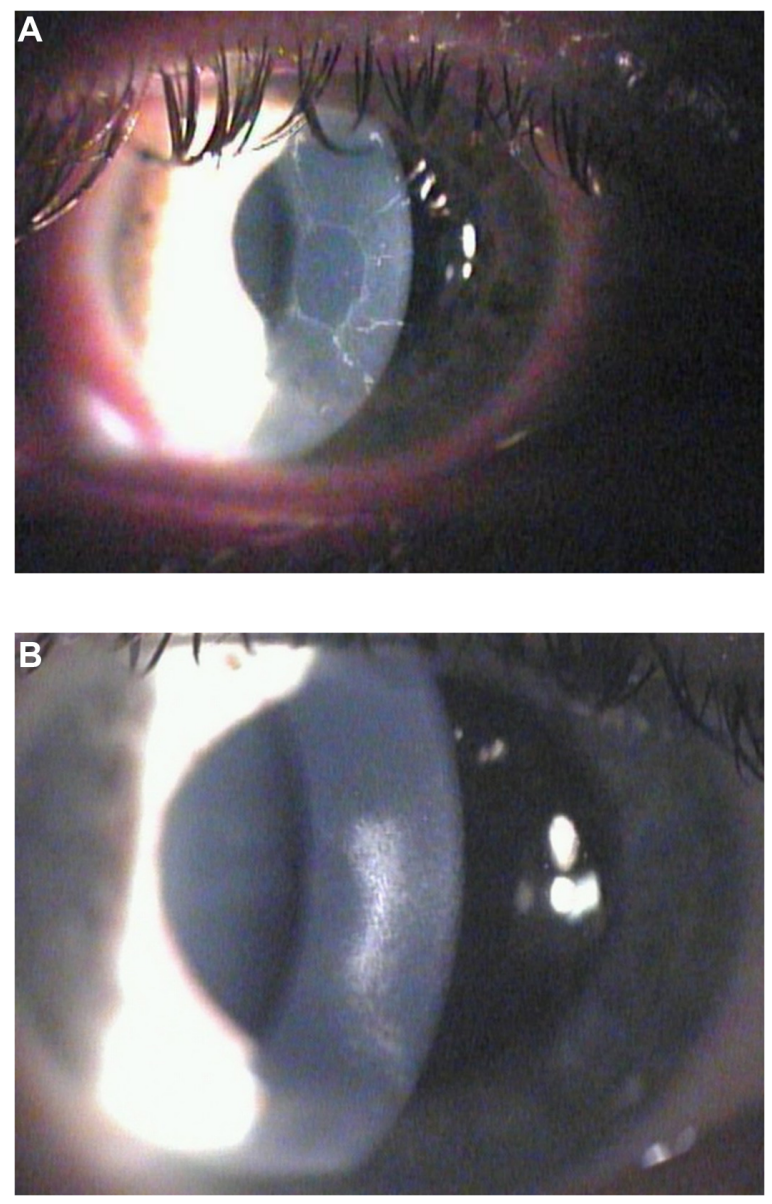

Figure I (Continued)

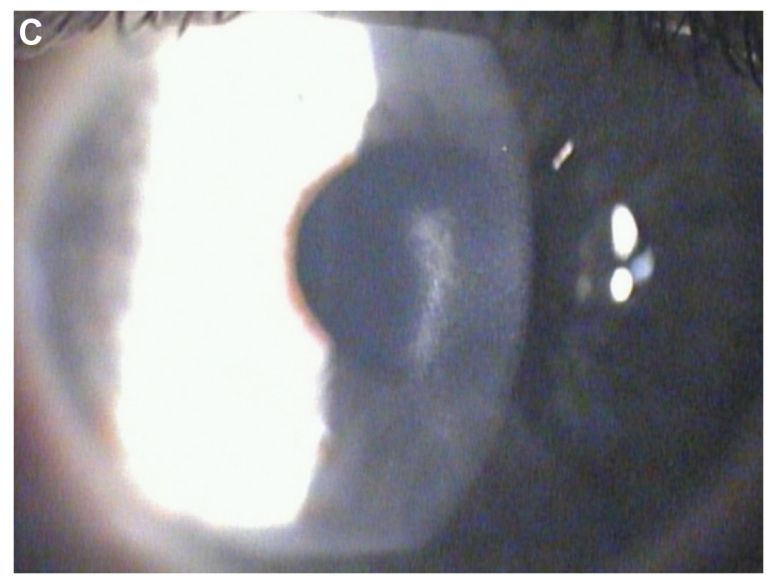

Figure I Biomicroscopic image of the right eye of a 31-year-old female patient with type I diabetes. (A) One week after myopic photorefractive keratectomy. The central cornea presents a large area of de-epithelialization. (B) Six months after photorefractive keratectomy. The re-epithelialization is complete but is present as a dense linear central scar. (C) One year after photorefractive keratectomy. The linear central scar is considerably reduced but is still visible.

occur after glycemic control in diabetic patients with severe hyperglycemia. The degree of transient hyperopia is highly dependent on $\mathrm{HbA}_{1 \mathrm{c}}$ levels before treatment and the rate of reduction of glucose levels over the first 7 days of treatment. This is probably due to decreased refractive power by lens hydration rather than morphological changes in the lens. ${ }^{52}$ Another recent study showed that refraction and visual acuity test results were highly reproducible and stable in patients with reasonably well controlled diabetes but with variable blood glucose levels under routine care. ${ }^{53}$ This problem can be easily corrected by getting a new pair of lenses or glasses, but not with the permanent changes following refractive surgery. Thus, good blood glucose control is important before and after refractive surgery.

\section{Corneal ablation is less predictable}

Some studies indicate a favorable refractive outcome after LASIK in patients with diabetes. However, $10 \%-28 \%$ of eyes required enhancement surgery. ${ }^{54-56}$ The reason for the higher enhancement rates in diabetic eyes is not clear. It is possible that ultrastructural changes occurring in the corneas of diabetic patients, ${ }^{57}$ together with changes in stromal hydration because of the dysfunctional endothelium, ${ }^{21,58}$ cause the eyes to respond differently to laser energy. Thus, usual nomograms may not be accurate in diabetic patients. ${ }^{55,56}$

\section{Slower healing of the cornea after surgery}

Abnormalities in the cornea are common in diabetes, and may lead to slow or imperfect healing after refractive surgery. 
Delayed epithelial healing, persistent epithelial defects, neurotrophic changes, and persistent erosions after LASIK and PRK may last a long time. Fraunfelder and Rich reported that, in 30 eyes of patients with diabetes, nine developed punctuate epithelial erosions and six developed persistent epithelial defects after LASIK, with a statistically significant rate of epithelial complications in diabetic eyes compared with the control group (47\% versus $6.9 \%, P<0.01$ ), as well as poorer refractive outcomes. ${ }^{1}$ Cobo-Soriano et al described 44 eyes of diabetic patients with a low incidence of anatomic complications after LASIK, ie, one case of intraoperative de-epithelialization, two cases of postoperative superficial punctate keratopathy, one case of mild epithelial ingrowth, and one of a peripheral interface reaction, all of which resolved without significant sequelae. ${ }^{2}$ In addition, visual and refractive results and number of postoperative visits did not differ significantly from those in the control group. The different results reported by these studies can be attributed to differences in the myopia range and in the refractive measurement parameters used. Epithelial complications after LASIK may occur during surgery as a result of pre-existing clinical or subclinical epithelial basement membrane dystrophy ${ }^{59-61}$ and the shearing force of microkeratome to the epithelium, ${ }^{62}$ or after surgery as result of the damage to the corneal nerves, causing dry eye ${ }^{63}$ and neurotrophic epitheliopathy. ${ }^{64}$ Fraunfelder and Rich attributed the epithelial complications in their case series to pre-existence of diabetic keratopathy, which was exacerbated by LASIK. ${ }^{1}$ In contrast with these results, Halkiadakis et al noted short-term safety of LASIK in patients with well controlled diabetes. ${ }^{54}$ No significant epithelial complications were encountered after 46 primary surgeries and 13 enhancements.

Several explanations might account for the different results. It has been suggested that intraoperative epithelial defects increase significantly with advancing age. ${ }^{62}$ In the study by Halkiadakis et al, the average age of the diabetic patients was 42 years, whereas in the Fraunfelder and Rich study, the average age was 10 years older. Moreover, different microkeratomes were used in the two studies. In the Fraunfelder and Rich study, the Nidek microkeratome was used. In the study by Halkiadakis et al, the Hansatome was the microkeratome of choice. Previous studies have indicated that the Nidek microkeratome is safe, predictable, and reliable for LASIK, ${ }^{65-67}$ and no significant differences with the Hansatome were found. However, it is of note that the zero-compression head reduced the occurrence of Hansatome-induced epithelial defects. ${ }^{68}$ The major disadvantages of LASIK are related to the creation of the lamellar flap.
Compared with PRK, LASIK produces more reduction of the biomechanical stability of the cornea. LASIK complications include free, incomplete, irregular, thin, or buttonholed flaps and keratectasia. ${ }^{69}$ However, one study in poorly controlled diabetics reported that corneal biomechanics were significantly greater compared with those in healthy subjects and patients with well controlled diabetes, and with a correlation to $\mathrm{HbA}_{1 \mathrm{c}}$. This suggests that the biomechanical properties of the cornea are altered depending on glucose control. ${ }^{70}$ Therefore, diabetes might be protective against keratectasia and its progression because this condition increases the number of corneal collagen cross-links in a manner similar to that of treatment of progressive keratoconus by means of collagen corneal crosslinking with riboflavin and ultraviolet $\mathrm{A} .{ }^{71}$

\section{Rate of epithelial ingrowth in patients with diabetes is higher than expected}

Epithelial ingrowth has been reported to occur in $0.5 \%$ of eyes in patients without diabetes. ${ }^{72,73}$ Jabbur et al ${ }^{74}$ recently reported that type 1 diabetes mellitus may increase the risk of epithelial ingrowth because of its effects on the corneal epithelium. They cautioned all refractive surgeons not to perform lamellar surgery on patients with type 1 diabetes or those with uncontrolled diabetes. However, Halkiadakis et al did not find any significant differences in refractive outcomes or complications between patients with type 1 versus those with type 2 diabetes. ${ }^{54}$

\section{Alteration of corneal innervation}

LASIK is associated with an iatrogenic dry eye syndrome known as LASIK-induced neurotrophic epitheliopathy, ${ }^{64}$ which might worsen pre-existing dry eye. It has been thought that diabetic keratopathy represents a form of diabetic neuropathy ${ }^{20}$ and that impairment of corneal sensitivity in people with diabetes is in direct correlation with the degree of polyneuropathy, ${ }^{20,26,75}$ duration of diabetes, ${ }^{76}$ and stage of diabetic retinopathy. ${ }^{23,77,78}$ The reason that neurotrophic changes occur in the corneas of patients with diabetes is an area of active study. Diabetic keratopathy is thought to be related to an aldose reductase-catalyzed reaction and polyol accumulation in the cornea. Corneas of patients with diabetes are exposed to increased glucose concentrations, which may contribute to accumulation of advanced glycation end products. ${ }^{79}$ Advanced glycation end products appear to accumulate on the basement membrane (particularly laminin), and studies of corneas in rabbits and humans with diabetes have shown the basement membrane to be thickened. There are also increased mitochondria and glycogen levels in the 
epithelial cells, leading to epithelial edema. ${ }^{80}$ An abnormal basement membrane in combination with edematous epithelial cells may be responsible for the poor epithelial healing and persistent epithelial defects in the corneas of patients with diabetes. Recently, aldose reductase, the first enzyme of the polyol pathway, has been shown to have an important role in the pathogenesis of decreased corneal sensitivity. ${ }^{81}$ Indeed, aldose reductase inhibitors may play a role in the treatment of diabetic keratopathy. Animal studies have shown that oral administration of SNK-860 (an aldose reductase inhibitor) prevents corneal damage induced via the polyol pathway by quickly reducing the polyol level in the corneal epithelium. ${ }^{82}$ A human study using CT-112 (a newly synthesized aldose reductase inhibitor) showed healing of persistent corneal epithelial defects in two patients with diabetes after 2-4 weeks of topical treatment. ${ }^{83}$

\section{Worsening of retinopathy}

LASIK may further damage the retina in people with diabetic retinopathy. At one point in the LASIK procedure, suction is applied to the eye. This suction causes increased pressure in the eye, and can be potentially harmful in some patients with diabetes. Also, using femtosecond laser during application of the suction ring, intraocular pressure can increase up to critical values. Vetter et al reported that maximum intraocular pressure values were higher when using the Amadeus mechanical microkeratome versus the IntraLase femtosecond laser (mean $152 \pm 24 \mathrm{mmHg}$ versus $135 \pm 16 \mathrm{mmHg}$ ) during flap preparation, but the duration of the suction phase was higher when using the femtosecond laser (mean $113 \pm 16$ seconds versus $39 \pm 7$ seconds). ${ }^{84}$ Halkiadakis et al did not observe retinopathy in eyes without retinopathy or aggravation of retinopathy in two eyes with background retinopathy during short-term follow-up. ${ }^{54}$ In contrast, Ghanbari and Ahmadieh ${ }^{85}$ recently reported aggravation of proliferative diabetic retinopathy after LASIK. They attributed the progression of retinopathy to the increase of retinal ischemia during suction. Although Halkiadakis et al did not note any progress in retinopathy in their patients, their study did not provide clues about the safety of performing LASIK in patients with significant diabetic retinopathy.

\section{Recommendations}

Statistics show that diabetic people have a significantly greater incidence of complications after a refractive surgical procedure as compared with people without diabetes. This alarming statistic highlights the need to exercise extra caution when considering laser refractive surgery in people with diabetes. Prior to performing any refractive surgery procedure, potential candidates will need to go through extremely thorough screening to ensure that they can have successful refractive surgery. Detailed retinal assessment, close examination with a slit-lamp, and tear film and epithelial tests can lower the high complication rate in individuals with diabetes who undergo laser surgery. Patients with diabetes should be informed of their increased risk of postoperative complications, and the clinician should proceed conservatively in this patient population to avoid adverse events. Thorough screening of a diabetic patient before undertaking refractive eye surgery is mandatory. First, the patient must have his/her diabetes under good control. Second, the patient must not have pre-existing diabetic ocular complications, such as an unhealthy ocular surface, cataracts, retinopathy of any sort, fragile retinal vasculature, or neovascularization secondary to the diabetes.

In diabetic patients, because of the mechanism of healing in which the corneal stroma is exposed during a significant postoperative period until re-epithelialization is complete, PRK is less indicated in comparison with LASIK, where the healing process is markedly improved. ${ }^{2}$ Differences in the technique may also play a role in the prevention of epithelial complications in predisposed eyes. It is better to avoid the use of drops, specifically topical anesthetic agents, one week preoperatively because they may increase epithelial fragility. ${ }^{59}$ Excessive irrigation of the stromal bed should also be avoided, and sodium hyaluronate drops can be instilled after repositioning of the flap.

Many preclinical and clinical trials have shown that certain growth factors and cytokines can significantly enhance epithelial proliferation and migration, with consequent acceleration of wound healing. More recently, local/topical administration of insulin, naltrexone (opioid antagonist) or nicergoline (an ergoline derivative) has been found to improve or significantly increase the corneal wound healing rate. These growth factors and therapeutic agents could ameliorate impaired corneal wound healing, and raise the possibility of clinical use of these agents as a new generation of ophthalmic pharmaceuticals for the treatment of diabetic keratopathy. ${ }^{86}$

\section{Conclusion}

Although it is well established that some systemic diseases are contraindications for refractive surgery, an analysis of the literature reveals a surprising shortage of clinical studies that demonstrate a potentially damaging effect of these diseases on corneal healing, and most publications are based on single 
anecdotal reports or small series. The bottom line is that no patient with diabetes is an ideal candidate for laser refractive surgery. However, some patients with diabetes might be at least reasonable candidates.

Patients with diabetes who desire laser refractive surgery for elective correction of vision represent a challenging treatment dilemma. Currently, the FDA and the American Academy of Ophthalmology have a broad recommendation that includes diabetes among the relative contraindications to LASIK and PRK surgery, predominantly due to concerns that the comorbid ocular conditions associated with the disease might lead to poor refractive outcomes and significant postoperative complications. However, we can assume that in a very select group of patients with diabetes, laser refractive surgery may be safely performed as long as the surgeon undertakes a thorough preoperative assessment of the status of the patient's systemic disease and the presence of associated ocular manifestations.

\section{Acknowledgment}

Financial support for this study was received from the Department of Biotechnological and Applied Clinical Sciences, University of L'Aquila, L'Aquila, Italy.

\section{Disclosure}

The authors report no conflicts of interest in this work.

\section{References}

1. Fraunfelder FW, Rich LF. Laser-assisted in situ keratomileusis complications in diabetes mellitus. Cornea. 2002;21:246-248.

2. Cobo-Soriano R, Beltran J, Baviera J. LASIK outcomes in patients with underlying systemic contraindications. Ophthalmology. 2006;113:1118-1124.

3. United States Food and Drug Administration. Medical devices. When is LASIK not for me? Available from: http://www.fda.gov/ medicaldevices/productsandmedicalprocedures/surgeryandlifesupport/ lasik/ucm061366.htm. Accessed July 18, 2012.

4. American Academy of Ophthalmology Refractive Errors Panel. Refractive Errors. San Francisco, CA: American Academy of Ophthalmology; 2002.

5. Leem HS, Lee KJ, Shin KC. Central corneal thickness and corneal endothelial cell changes caused by contact lens use in diabetic patients. Yonsei Med J. 2011;52:322-325.

6. Tai ES, Lim SC, Tan BY, et al. Screening for diabetes mellitus a two step approach in individuals with impaired fasting glucose improves detection of those at risk of complications. Diabetes Med. 2000;17:771-775.

7. Graff MR, Rubin RR, Walker EA. How diabetes specialists treat their own diabetes: findings from a study of the AADE and ADA membership. Diabetes Educ. 2000;26:460-467.

8. Klein R, Klein BEK. Diabetic eye disease. Lancet. 1997;350:197-204.

9. Guillausseau PJ, Massin P, Charles MA, et al. Glycaemic control and development of retinopathy in type 2 diabetes mellitus: a longitudinal study. Diabet Med. 1998;152:151-155.

10. Turner R. Intensive blood-glucose control with sulphonylureas or insulin compared with conventional treatment and risk of complications in patients with type 2 diabetes (UKPDS 33). Lancet. 1998;352:837-853.
11. Stratton IM, Kohner EM, Aldington SJ, et al. UKPDS 50: risk factors for incidence and progression of retinopathy in type II diabetes over 6 years from diagnosis. Diabetologia. 2001;44:156-163.

12. Kaji Y. Prevention of diabetic keratopathy. Br J Ophthalmol. 2005;89: 254-255.

13. Niffenegger JH, Fong D, Cavallerano J, Aiello LM. Diabetes mellitus. In: Albert DM, Jakobiec FA, editors. Principles and Practice of Ophthalmology. Philadelphia, PA: Saunders; 1994.

14. Harding JJ, Egerton M, van Heyningen R, Harding RS. Diabetes, glaucoma, sex, and cataract: analysis of combined data from two case control studies. Br J Ophthalmol. 1993;77:2-6.

15. Kahn HA, Leibowitz HM, Ganley JP, et al. The Framingham Eye Study. II. Association of ophthalmic pathology with single variables previously measured in the Framingham Heart Study. Am J Epidemiol. 1977;106:33-41.

16. Stanga PE, Boyd SR, Hamilton AM. Ocular manifestations of diabetes mellitus. Curr Opin Ophthalmol. 1999;10:483-489.

17. Tabin G, Chen M, Espandar L. Cataract surgery for the developing world. Curr Opin Ophthalmol. 2008;19:55-59.

18. Bikbova G, Oshitari T, Tawada A, Yamamoto S. Corneal changes in diabetes mellitus. Curr Diabetes Rev. 2012;8:294-302.

19. Hyndiuk RA, Kazarian EL, Schultz RO, Seideman S. Neurotrophic corneal ulcers in diabetes mellitus. Arch Ophthalmol. 1977;95: 2193-2196.

20. Schultz RO, Peters MA, Sobocinski K, Nassif K, Schultz KJ. Diabetic keratopathy as a manifestation of peripheral neuropathy. $\mathrm{Am} \mathrm{J}$ Ophthalmol. 1983;96:368-371.

21. Schultz RO, Matsuda M, Yee RW, Edelhauser HF, Schultz KJ. Corneal endothelial changes in type I and type II diabetes mellitus. $\mathrm{Am} J$ Ophthalmol. 1984;98:401-410.

22. Herse PR. A review of manifestations of diabetes mellitus in the anterior eye and cornea. Am J Optom Physiol Opt. 1988;65:224-230.

23. Saini JS, Khandalavla B. Corneal epithelial fragility in diabetes mellitus. Can J Ophthalmol. 1995;30:142-146.

24. Sanchez-Thorin JC. The cornea in diabetes mellitus. Int Ophthalmol Clin. 1998;38:19-36.

25. Goebbels M. Tear secretion and tear film function in insulin dependent diabetics. Br J Ophthalmol. 2000;84:19-21.

26. Dogru M, Katakami C, Inoue M. Tear function and ocular surface changes in noninsulin-dependent diabetes mellitus. Ophthalmology. 2001;108:586-592.

27. Tsubota K, Yamada M. The effect of aldose reductase inhibitor on the corneal epithelium. Cornea. 1993;12:161-162.

28. Meyer LA, Ubels JL, Edelhauser HF. Corneal endothelial morphology in the rat. Effects of aging, diabetes, and topical aldose reductase inhibitor treatment. Invest Ophthalmol Vis Sci. 1988;29:940-948.

29. Hosotani H, Ohashi Y, Yamada M, Tsubota K. Reversal of abnormal corneal epithelial cell morphologic characteristics and reduced corneal sensitivity in diabetic patients by aldose reductase inhibitor, CT-112. Am J Ophthalmol. 1995;119:288-294.

30. Kenyon K, Wafai Z, Michels R, et al. Corneal basement membrane abnormality in diabetes mellitus [ARVO abstract]. Invest Ophthalmol Vis Sci. 1978;Suppl 17:245.

31. Azar DT, Spurr-Michaud SJ, Tisdale AS, et al. Altered epithelialbasement membrane interactions in diabetic corneas. Arch Ophthalmol. 1992;110:537-540.

32. Gipson IK, Spurr-Mirchaud SJ, Tisdale AS. Anchoring fibrils form a complex network in human and rabbit corneas. Invest Ophthalmol Vis Sci. 1987;289:212-221.

33. Azar DT, Spurr-Michaud SJ, Tisdale AS, et al. Decreased penetration of anchoring fibrils into the diabetic stroma. A morphometric analysis. Arch Ophthalmol. 1989;107:1520-1523.

34. Chen WL, Lin CT, Ko PS, et al. In vivo confocal microscopic findings of corneal wound healing after corneal epithelial debridement in diabetic vitrectomy. Ophthalmology. 2001;116:1038-1047.

35. Gekka M, Miyata K, Nagai Y, et al. Corneal epithelial barrier function in diabetic patients. Cornea. 2004;23:35-37. 
36. Gobbels M, Spitznas M, Oldendoerp J. Impairment of corneal epithelial barrier function in diabetics. Graefes Arch Clin Exp Ophthalmol. 1989;227:142-144.

37. Yokoi N, Niiya A, Komuro A, et al. Effects of aldose reductase inhibitor CT-112 on the corneal epithelial barrier of galactose-fed rats. Curr Eye Res. 1997;16:595-599.

38. Schultz RO, Peters MA, Sobocinski K, et al. Diabetic corneal neuropathy. Trans Am Ophthalmol Soc. 1983;81:107-124.

39. Davidson EP, Coppey LJ, Holmes A, Yorek MA. Changes in corneal innervation and sensitivity and acetylcholine-mediated vascular relaxation of the posterior ciliary artery in a type 2 diabetic rat. Invest Ophthalmol Vis Sci. 2012;53:1182-1187.

40. Hosotani H, Ohashi Y, Kinoshita S, et al. Effects of topical aldose reductase inhibitor CT-112 on corneal sensitivity of diabetic rats. Curr Eye Res. 1996;15:1005-1007.

41. Fujishima H, Shimazaki J, Yagi Y, et al. Improvement of corneal sensation and tear dynamics in diabetic patients by oral aldose reductase inhibitor, ONO-2235: a preliminary study. Cornea. 1996;15:368-375.

42. Daubs JG. Diabetes screening with corneal aesthesiometer. Am J Optom Physiol Opt. 1975;52:31-35.

43. Parrish GM. The cornea in diabetes mellitus. In: Ferman SS, editor. Ocular Problems in Diabetes Mellitus. Boston, MA: Blackwell Scientific; 1992

44. Sigelman S, Friedenwald J. Mitotic and wound healing activities of the corneal epithelium. Effect of sensory denervation. Arch Ophthalmol. 1954;52:46-57.

45. Ohguro N, Matsuda M, Ohashi Y, et al. Topical aldose reductase inhibitor for correcting corneal endothelial changes in diabetic patients. Br J Ophthalmol. 1995;79:1074-1077.

46. Rao GN, Lohman LE. Cell size-shape relationships in corneal endothelium. Invest Ophthalmol Vis Sci. 1982;22:271-274.

47. Shaw EL, Rao GN, Arthur EJ, Aquavella JV. Endothelial cell morphology and corneal deturgescence. Ann Ophthalmol. 1979;11:885-899.

48. Delamaire M, Maugendre D, Moreno M, Le Goff MC, Allannic H, Genetet B. Impaired leucocyte functions in diabetic patients. Diabet Med. 1997;14:29.

49. Llorente L, De La Fuente H, Richaud-Patin Y, et al. Innate immune response mechanisms in non-insulin dependent diabetes mellitus patients assessed by flow cytoenzymology. Immunol Lett. 2000;74:239-244.

50. Schillie SF, Xing J, Murphy TV, Hu DJ. Prevalence of hepatitis B virus infection among persons with diagnosed diabetes mellitus in the United States, 1999-2010. J Viral Hepat. 2012;19:674-676.

51. Ata A, Lee J, Bestle SL, Desemone J, Stain SC. Postoperative hyperglycemia and surgical site infection in general surgery patients. Arch Surg. 2010;145:858-864.

52. Li HY, Luo GC, Guo J, Liang Z. Effects of glycemic control on ophthalmic refraction in diabetic patients. Int J Ophthalmol. 2010;3: $158-160$.

53. Agardh E, Hellgren KJ, Bengtsson B. Stable refraction and visual acuity in diabetic patients with variable glucose levels under routine care. Acta Ophthalmol. 2011;89:107-110.

54. Halkiadakis I, Belfair N, Gimbel HV. Laser in situ keratomileusis in patients with diabetes. J Cataract Refract Surg. 2005;31: 1895-1898.

55. Hersh PS, Fry KL, Bishop DS. Incidence and associations of retreatment after LASIK. Ophthalmology. 2003;110:748-754.

56. Netto MV, Wilson SE. Flap lift for LASIK retreatment in eyes with myopia. Ophthalmology. 2004;111:1362-1367.

57. Rehany U, Ishii Y, Lahav M, Rumelt S. Ultrastructural changes in corneas of diabetic patients; an electron-microscopy study. Cornea. 2000;19:534-538.

58. Saini JS, Mittal S. In vivo assessment of corneal endothelial function in diabetes mellitus. Arch Ophthalmol. 1996;114:649-653.

59. Dastgheib KA, Clinch TE, Manche EE, Hersh P, Ramsey J. Sloughing of corneal epithelium and wound healing complications associated with laser in situ keratomileusis in patients with epithelial basement membrane dystrophy. Am J Ophthalmol. 2000;130:297-303.
60. Rezende RA, Uchoa UC, Cohen EJ, Laibson PR, Rapuano CJ. Complications associated with anterior basement membrane dystrophy after laser in situ keratomileusis. J Cataract Refract Surg. 2004;30: 2328-2331.

61. Kenyon KR, Paz H, Greiner JV, Gipson IK. Corneal epithelial adhesion abnormalities associated with LASIK. Ophthalmology. 2004; 111:11-17.

62. Tekwani NH, Huang D. Risk factors for intraoperative epithelial defect in laser in-situ keratomileusis. Am J Ophthalmol. 2002;134:311-316.

63. Toda I, Asano-Kato N, Komai-Hori Y, Tsubota K. Dry eye after laser in situ keratomileusis. Am J Ophthalmol. 2001;132:1-7.

64. Wilson SE. Laser in situ keratomileusis-induced (presumed) neurotrophic epitheliopathy. Ophthalmology. 2001;108:1082-1087.

65. Schumer DJ, Bains HS. The Nidek MK-2000 microkeratome system. $J$ Refract Surg. 2001;17:S250-S251.

66. Sarkisian KA, Petrov AA. Experience with the Nidek MK-2000 microkeratome in 1220 cases. $J$ Refract Surg. 2001;17:S252-S254.

67. Nakano K, Nakano E, Oliveira M, Portellinha W, Alvarenga L. Intraoperative microkeratome complications in 47,094 laser in situ keratomileusis surgeries. J Refract Surg. 2004;20:S723-S726.

68. Kohnen T, Terzi E, Mirshahi A, Buhren J. Intraindividual comparison of epithelial defects during laser in situ keratomileusis using standard and zero compression Hansatome microkeratome heads. $J$ Cataract Refract Surg. 2004;30:123-126.

69. Spadea L, Cantera E, Cortes M, Evangelista Conocchia N, Stewart CW. Corneal ectasia after myopic laser in situ keratomileusis: a long term study. Clin Ophthalmol. 2012;6:1801-1813.

70. Scheler A, Spoerl E, Boehm AG. Effect of diabetes mellitus on corneal biomechanics and measurement of intraocular pressure. Acta Ophthalmol. 2012;90:e447-e451.

71. Spadea L, Mencucci R. Transepithelial corneal collagen cross-linking in ultrathin keratoconic corneas. Clin Ophthalmol. 2012;6:1785-1792.

72. Wang MY, Maloney RK. Epithelial ingrowth after laser in situ keratomileusis. Am J Ophthalmol. 2000;129:746-751.

73. Stulting RD, Carr JD, Thompson KP, et al. Complications of laser in situ keratomileusis for the correction in myopia. Ophthalmology. 1999;106:13-20.

74. Jabbur NS, Chicani CF, Kuo IC, O'Brien TP. Risk factors in interface epithelialization after laser in situ keratomileusis. $J$ Refract Surg. 2004; 20:343-348.

75. Nielsen NV, Lund FS. Diabetic polyneuropathy; corneal sensitivity, vibratory perception and Achilles tendon reflex in diabetics. Acta Neurol Scand. 1979;59:15-22.

76. Rosenberg ME, Tervo TMT, Immonen IJ, Muller LJ, Gronhagen-Riska C, Vesaluoma MH. Corneal structure and sensitivity in type 1 diabetes mellitus. Invest Ophthalmol Vis Sci. 2000;41:2915-2921.

77. Saito J, Enoki M, Hara M, Morishige N, Chikama T, Nishida T. Correlation of corneal sensation, but not of basal or reflex tear secretion, with the stage of diabetic retinopathy. Cornea. 2003;22:15-18.

78. Ozdemir M, Buyukbese MA, Cetinkaya A, Ozdemir G. Risk factors for ocular surface disorders in patients with diabetes mellitus. Diabetes Res Clin Pract. 2003;59:195-199.

79. Kaji Y, Usui T, Oshika T, et al. Advance glycation end products in diabetic corneas. Invest Ophthalmol Vis Sci. 2000;41:362-368.

80. Jiang D, He Y, Mai C. A study on the course of corneal epithelial healing in diabetic rabbits. Zhonghua Yan Ke Za Zhi. 1996;32:255-257. Chinese.

81. Jacot JL, Hosotani H, Glover JP, Lois N, Robison WG Jr. Diabetic-like corneal sensitivity loss in galactose fed rats ameliorated with aldose reductase inhibitors. J Ocul Pharmacol Ther. 1998;14:169-180.

82. Kubo E, Nakamura S, Tsuzuki S, et al. Inhibitory effect of orally administered aldose reductase inhibitor SNK-860 on corneal polyol accumulation in galactose-fed rats. Graefes Arch Clin Exp Ophthalmol. 1999;237:758-762.

83. Ohashi Y, Matsuda M, Hosotani H, et al. Aldose reductase inhibitor (CT-112) eyedrops for diabetic corneal epitheliopathy. Am J Ophthalmol. 1988;105:233-238. 
84. Vetter JM, Schirra A, Garcia-Bardon D, Lorenz K, Weingärtner WE, Sekundo W. Comparison of intraocular pressure during corneal flap preparation between a femtosecond laser and a mechanical microkeratome in porcine eyes. Cornea. 2011;30:1150-1154.

85. Ghanbari H, Ahmadieh H. Aggravation of proliferative diabetic retinopathy after laser in situ keratomileusis. J Cataract Refract Surg. 2003;29:2232-2233.
86. Abdelkader H, Patel DV, McGhee CNJ, Alany RG. New therapeutic approaches in the treatment of diabetic keratopathy: a review. Clin Experiment Ophthalmol. 2011;39:259-270.

\section{Publish your work in this journal}

Clinical Ophthalmology is an international, peer-reviewed journal covering all subspecialties within ophthalmology. Key topics include: Optometry; Visual science; Pharmacology and drug therapy in eye diseases; Basic Sciences; Primary and Secondary eye care; Patien Safety and Quality of Care Improvements. This journal is indexed on

Submit your manuscript here: http://www.dovepress.com/clinical-ophthalmology-journal

\section{Dovepress}

PubMed Central and CAS, and is the official journal of The Society of Clinical Ophthalmology (SCO). The manuscript management system is completely online and includes a very quick and fair peer-review system, which is all easy to use. Visit http://www.dovepress.com/ testimonials.php to read real quotes from published authors. 